Correction

\title{
Correction: "Ahmed H. Touny, Mahmoud M. Saleh, Enhanced Methanol Oxidation on Nanoporous Nickel Phosphate Modified Platinum Electrode in Alkaline Solution" [Int. J. Electrochem. Sci., 13 (2018) 1042 -1050]
}

Ahmed. H. Touny ${ }^{1,3, *}$, Mahmoud. M. Saleh ${ }^{1,2, *}$

${ }^{1}$ Department of Chemistry, College of Science, King Faisal University, Al-Hassa, Saudi Arabia

${ }^{2}$ Department of Chemistry, Faculty of Science, Cairo University, Cairo, Egypt

${ }^{3}$ Department of Chemistry, Faculty of Science, Helwan University, Helwan, Egypt

5 November 2018

In page 1049 in the Acknowledgement part. The project number was written as \#100754

The correction is: The project \# 100759.

(C) 2018 Published by ESG (www.electrochemsci.org). 